\title{
Gender Differences in the Clinical Manifestations and Prognosis of Patients Hospitalized with Acute Exacerbations of Chronic Obstructive Pulmonary Disease
}

\author{
S Yu ${ }^{1}$, Q Fang ${ }^{1}, \mathrm{Y} \mathrm{Ma}^{2}, \mathrm{R} \mathrm{Li}^{1}, \mathrm{~L} \mathrm{Guo}^{1}$
}

\begin{abstract}
Objective: To explore gender differences in the clinical manifestations of patients hospitalized with acute exacerbations of chronic obstructive pulmonary disease (AECOPD), and to find independent risk factors for their prognosis.

Methods: Data from a retrospective study were analysed. Patients diagnosed with AECOPD were consecutively enrolled from a respiratory ward from October 2010 to March 2012. The following clinical data were evaluated: body mass index (BMI), arterial blood gas analysis, pulmonary function test during hospitalization or last pulmonary function test result before admission and exercise capacity. All data were analysed using SPSS 13.0 statistical software. P-values of $<0.05$ were considered statistically significant.

Results: One hundred and fifty-one patients hospitalized with AECOPD were enrolled. There were no significant gender differences in age, BMI, length of hospitalization, family history, exercise capacity, respiratory failure, factors causing AECOPD, the number of antibiotics used during hospitalization or COPD severity grade. Statistically significant differences were observed for cigarette smoking history, the first clinical manifestations of the disease and chronic co-morbidities by gender. Gender was not an independent risk factor for short- or long-term prognosis.

Conclusions: In patients hospitalized with AECOPD, there was statistical significance by gender for the first symptom of the disease. Significantly more males were cigarette smokers than females. Regarding co-morbidities, the frequency of hypertension, diabetes mellitus and ischaemic heart disease were significantly greater in females. For patients hospitalized with AECOPD, gender was not an independent risk factor for short- or long-term prognosis.
\end{abstract}

Keywords: Acute exacerbations, AECOPD, chronic obstructive pulmonary disease, clinical manifestations, gender differences, prognosis

WIMJ Open 2014; 1 (1): 1

\section{INTRODUCTION}

Worldwide, chronic obstructive pulmonary disease (COPD) has become the third most common cause of hospitalization, the fourth most common cause of death, and the only leading cause of death that is increasing (1). Acute exacerbations of COPD (AECOPD) are associated with hospitalizations and have become an important reason for poor prognosis and death of patients with COPD. Since the 1980s, there has been an increase in the incidence, prevalence and mortality of COPD in women (2-4). As a result, a number of studies have

From: ${ }^{1}$ Department of Respiratory and Critical Care Medicine, Beijing Shijitan Hospital, Capital Medical University, Beijing, China and ${ }^{2}$ Department of Respiratory and Critical Care Medicine, Beijing Chaoyang Hospital, Capital Medical University, Beijing, China.

Correspondence: Dr Q Fang, Department of Respiratory and Critical Care Medicine, Beijing Shijitan Hospital, Capital Medical University, Tieyilu 10, Yangfangdian, Haidian District, Beijing 100038, China. E-mail: florence408@126.com examined gender differences in the clinical manifestations, treatment and prognosis. But until now, whether gender differences exist in patients hospitalized with AECOPD has been rarely reported. The global strategy for the diagnosis, management, and prevention of COPD [revised in 2011] (5) emphasized the effect of AECOPD on the disease process and prognosis of patients. Understanding any gender differences in the clinical manifestations of patients hospitalized with AECOPD may therefore guide the development of individual treatments, improve the prognosis of patients, and make an important contribution to long-term hierarchical management. Therefore, we explored gender differences in the clinical manifestations and prognosis of patients hospitalized with AECOPD.

\section{SUBJECTS AND METHODS}

Baseline data from a retrospective study were analysed. Patients diagnosed with AECOPD who were admitted to the 
Department of Respiratory and Critical Care Medicine were consecutively enrolled from October 2010 to March 2012. The diagnosis of COPD and AECOPD, and grade of COPD were defined by the standards set out by the respiratory branch of the Chinese Medical Association [revised in 2007] (6).

\section{Clinical data collection}

Clinical data for each patient were collected, including gender, age, body mass index (BMI), educational level, cigarette smoking history, family history, definitely diagnosed co-morbidities, factors causing AECOPD, the degree of dyspnoea and the first clinical manifestations of the disease.

\section{Pulmonary function test}

Patients were tested by an experienced technician during hospitalization after anti-infective therapy, using a Jaeger pulmonary function tester made in Germany. Each patient was tested before and after inhalation of salbutamol sulfate $200 \mu \mathrm{g}$, with a time interval of 15 minutes. The latest pulmonary function test result of the patients was reviewed once they were stable.

\section{Arterial blood gas test}

Patients were tested on the day of admission without oxygen, using a Nova biomedical arterial blood gas tester. Patients who were critical received the test with low-flow oxygen (2 $\mathrm{L} / \mathrm{min})$.

\section{Assessment of dyspnoea}

Patients were evaluated using the modified Medical Research Council (mMRC) dyspnoea scoring scale.

\section{Follow-up}

Patients were followed-up by telephone two weeks after discharge, to assess recurrence and drug compliance. $\mathrm{Pa}$ tients who were enrolled at the beginning of the study were followed-up for one year to observe the frequencies of hospitalization due to AECOPD.

\section{Statistical analysis}

All data were analysed using SPSS 13.0 statistical software. Differences in the evaluated parameters between gender groups were compared using the two-independent sample $t$ test, Chi-squared test or Fisher's exact test. Risk factors affecting the prognosis of those patients were identified by logistic regression analysis. $P$-values of $<0.05$ were considered statistically significant.

\section{RESULTS}

A total of 151 patients hospitalized with AECOPD were enrolled. This included $109(72.19 \%)$ males and 42 (27.81\%) females, with age range from 50 to 92 years, BMI from 14.20 to 42.37 , and duration of hospitalization from two to 71 days. Among the patients, there were no significant gender differences in age, BMI, length of hospitalization, family history, factors causing AECOPD, exercise capacity, respiratory failure, COPD severity grade, pathogenic bacteria and the number of antibiotics (Table 1). Statistically Table 1: Gender differences in general clinical data

\begin{tabular}{|c|c|c|c|}
\hline & Males & Females & $p$-value \\
\hline Age (years)* & $74.23 \pm 9.35$ & $76.90 \pm 7.15$ & 0.063 \\
\hline BMI $\left(\mathrm{kg} / \mathrm{m}^{2}\right) *$ & $23.29 \pm 4.54$ & $23.29 \pm 4.54$ & 0.216 \\
\hline Cigarette smoking history (cases) ${ }_{\Delta}$ & 98 & 24 & 0.000 \\
\hline Family history (cases) $)_{\Delta}$ & 34 & 16 & 0.419 \\
\hline Factors causing AECOPD (cases) $)_{\Delta}$ & 70 & 28 & 0.778 \\
\hline Positive sputum results (cases) $)_{\Delta}$ & 31 & 17 & 0.155 \\
\hline \multicolumn{4}{|l|}{ Graded by severity of COPD } \\
\hline Severe and very severe (cases) $)_{\Delta}$ & $86(78.90 \%)$ & $32(76.19 \%)$ & 0.718 \\
\hline \multicolumn{4}{|l|}{ Respiratory failure (cases) } \\
\hline Type $\mathrm{I}_{\Delta}$ & $8(7.34 \%)$ & $4(9.52 \%)$ & 0.913 \\
\hline Type $\mathrm{II}_{\Delta}$ & $28(25.69 \%)$ & $13(30.95 \%)$ & 0.515 \\
\hline mMRC dyspnoea scores $(\geq 2)_{\Delta}$ & $86(78.90 \%)$ & $34(80.95 \%)$ & 0.780 \\
\hline Number of antibiotics (cases) $)_{\Delta}$ & 42 & 15 & 0.794 \\
\hline Length of hospitalization (days)* & $11.58 \pm 8.31$ & $10.48 \pm 4.22$ & 0.415 \\
\hline
\end{tabular}

* value of two independent sample $t$-test, ${ }_{\Delta}$ value of the Chi-squared test or Fisher's exact test

BMI - body mass index, AECOPD - acute exacerbations of chronic obstructive pulmonary disease, mMRC - modified Medical Research Council

significant differences were observed between males and females for cigarette smoking history $(p<0.0001)$. For the first clinical manifestations of the disease, males were characterized by cough and expectoration, whereas females were characterized by wheezing. This difference was statistically significant (Table 2). For the chronic co-

Table 2: Gender differences in the first symptom

\begin{tabular}{lccc}
\hline & Males & Females & $\boldsymbol{p}$-value \\
\hline Cough and expectoration & $69.72 \%$ & $47.62 \%$ & 0.011 \\
Wheezing & $4.59 \%$ & $19.05 \%$ & 0.005 \\
Both of these symptoms & $25.69 \%$ & $33.33 \%$ & 0.347 \\
\hline
\end{tabular}

morbidities, the frequency of hypertension, Type 2 diabetes mellitus, ischaemic heart disease, cerebrovascular diseases and chronic renal insufficiency was greater in women; however, only the first three had significant gender differences (Table 3). There was no gender difference in mortality or prognosis (Table 4). The frequency of acute exacerbations in the past year and a positive sputum result during this time

Table 3: Gender differences in co-morbidities

\begin{tabular}{lccc}
\hline & Males & Females & $\boldsymbol{p}$-value \\
\hline Hypertension & $43.12 \%$ & $64.29 \%$ & 0.020 \\
Type 2 diabetes & $18.35 \%$ & $33.33 \%$ & 0.048 \\
Ischaemic heart disease & $27.52 \%$ & $45.24 \%$ & 0.037 \\
Chronic renal insufficiency & $4.59 \%$ & $4.76 \%$ & 0.963 \\
Cerebrovascular disease & $13.76 \%$ & $21.43 \%$ & 0.248 \\
\hline
\end{tabular}


Table 4: Gender differences in the prognosis of patients hospitalized with acute exacerbations of chronic obstructive pulmonary disease (AECOPD)

\begin{tabular}{cccc}
\hline & Males & Females & $\boldsymbol{p}$-value \\
\hline Two-week follow-up & & & \\
$\quad$ Recurrence (cases) & 14 & 6 & 0.815 \\
$\quad$ Mortality (\%) & $1.83 \%$ & $0 \%$ & 0.377 \\
$\begin{array}{c}\text { One-year follow-up } \\
\text { Recurrence (cases) }\end{array}$ & 36 & 14 & 0.954 \\
Mortality (\%) & $13.11 \%$ & $4.17 \%$ & 0.415 \\
\hline
\end{tabular}

were two independent risk factors affecting the short-term prognosis of patients hospitalized with AECOPD (Table 5). The frequency of acute exacerbations in the past year was the only inde-pendent risk factor of long-term prognosis (Table 6). Gender was not an independent risk factor for short- or long-term prognosis.

Table 5: Risk factors affecting short-term prognosis of patients hospitalized with acute exacerbations of chronic obstructive pulmonary disease (AECOPD)

\begin{tabular}{lccc}
\hline & Odds ratio & $\mathbf{9 5 \%}$ CI for B & $\boldsymbol{p}$-value \\
\hline Gender & 0.969 & $0.204,4.600$ & $0.968_{\#}$ \\
Frequencies of AE in the past year & 1.455 & $1.142,1.854$ & $0.002_{* *}$ \\
$\begin{array}{l}\text { Bacteriological results } \\
\quad \text { Bacterial infection }\end{array}$ & 0.100 & $0.018,0.553$ & $0.028_{* *}$ \\
$\quad$ Fungal infection & 0.411 & $0.058,2.906$ & 0.373 \\
$\quad$ Bacterial and fungal infection & 0.154 & $0.022,1.090$ & 0.061 \\
\hline
\end{tabular}

${ }^{\#} \mathrm{p}>0.05,{ }^{* *} \mathrm{p}<0.05$

Table 6: Risk factors affecting long-term prognosis of patients hospitalized with acute exacerbations of chronic obstructive pulmonary disease (AECOPD)

\begin{tabular}{lccc}
\hline & Odds ratio & $\mathbf{9 5 \%}$ CI for B & $\boldsymbol{p}$-value \\
\hline Gender & 1.649 & $0.513,5.301$ & $0.401_{\#}$ \\
Frequencies of AE in the past year & 1.643 & $1.113,2.426$ & $0.013_{* *}$ \\
\hline
\end{tabular}

${ }^{*} \mathrm{p}>0.05,{ }^{* *} \mathrm{p}<0.05$

\section{DISCUSSION}

Since the 1980s, the prevalence and mortality of females with COPD has increased significantly (2-4), which may exceed males $(3,4)$. With the number of female patients increasing, a number of studies have examined gender differences in patients with COPD.

In the present study, we found that the first clinical manifestations of patients with AECOPD showed significant gender differences, namely that males had cough and expectoration as the first symptom, whereas females had wheezing as their first symptom. Studies have reported gender differences in expectoration and dyspnoea in patients with COPD $(7,8)$. In the PLATINO study (9), females were more likely to show dyspnoea and a decline in activity tolerance, whereas males were more likely to exhibit cough and expectoration with the same degree of airway obstruc- tion. The results of our study confirm those of the PLATINO study.

We considered the mechanism underlying gender differences of the first clinical manifestations. First, neurobiology studies have shown that females have increased sensitivity to endogenous cytotoxicity, including dyspnoea; secondly, neuroimaging studies suggest that gender differences exist in the toxic stimulus processing carried out by one side of the prefrontal cortex; finally, tobacco exposure is an important risk factor for COPD. Because of the anatomical structure of the airway and physiological function, women are more susceptible to the toxic effects of tobacco. When exposed to the same dose of tobacco, females are more susceptible to the destruction of the alveolar structure which leads to a decline in lung function and dyspnoea.

We also observed that the frequency of hypertension, Type 2 diabetes, ischaemic heart disease, cerebrovascular disease and chronic renal insufficiency was greater in females, but only the first three were statistically significant. This result was different from the EPIDEPOC (10) and TORCH studies (2). With increasing age, the incidence of ischaemic heart disease in females increases. Because oestrogen levels decrease in older women, there is no difference in the incidence of vascular disease between men and women older than 60 years (11). Studies have shown that the incidence of ischaemic heart disease in females is negatively correlated with the level of androgen and progesterone, whereas the levels of androgen and progesterone in postmenopausal women were significantly higher than those of pre-menopausal women (12). The results of the present study were different from other studies for a number of reasons. First, there were differences in the study sample. Patients were outpatients in the EPIDEPOC and TORCH studies, whereas in our study patients came from the respiratory ward. Secondly, patients enrolled in our study were over 50 years of age, that is, all the females were postmenopausal and had lost the protective effect of oestrogen. Thirdly, females were more sensitive to discomfort than men (13), as seen with ischaemic heart diseases earlier. Finally, among all females in this study, smokers accounted for $57.14 \%$. Smoking can affect their lung function by changing hormone levels. Smoking induces the cytochrome P450 isozymes CYP1A1 and of CYP1A2, which can change the metabolism of oestrogen and increase inactive catecholamine levels (14). This may be an important factor in our study.

Recently, with more research in the phenotypes and subtypes of COPD, gender has become an important factor as different phenotypes of COPD patients have been reported (15). We observed that there were significant differences by gender in the first clinical manifestations and co-morbidities of patients hospitalized with AECOPD. This is similar to current studies of COPD phenotypes, so we considered that gender may be an important factor for differences in the clinical phenotypes of patients hospitalized with AECOPD. 
Some studies suggest that there are no significant gender differences in prognosis. Among COPD patients with cor pulmonale, Cooper et al (16) observed that there were no gender differences in the survival rate $(p=0.583)$. In the present study, gender was not an independent risk factor for short- or long-term prognosis. However, in a report from the national disease control centre, the annual number of deaths from COPD increased by $5 \%$ among men and by $11 \%$ among women from 2000 to 2005, which was statistically significant (17). Thus whether gender difference in the mortality of COPD exists remains in dispute.

We found that the frequencies of AECOPD in the past year and a positive result of sputum test were two independent risk factors of short-term prognosis of patients hospitalized with AECOPD. Many factors can cause AECOPD, including inhaling an environmental stimulus, heart failure and lack of treatment compliance; however, most acute exacerbations are caused by bacterial or viral infection (18). The increase in bacterial burden may lead to the aggravation of respiratory inflammation during AECOPD (19). If bacterial infection occurs in the airway, it can induce the release of inflammatory factors leading to oxidative stress which can destroy the balance of the proteinase system in the pulmonary tissue and airways, resulting in the aggravation of emphysema. Acute exacerbations of COPD-related hospitalization is a key event affecting the prognosis and survival rate of COPD patients (14). Arnedillo Muñoz observed that AECOPD could increase the mortality of patients with COPD in the short-term (20). The results of our study confirm these findings.

Acute exacerbations of COPD often appears in patients who have severe COPD or who have suffered repeated acute exacerbations, and it is an important factor leading to the rapid decrease of forced expiratory volume in the first second $\left(\mathrm{FEV}_{1}\right)$. Hurst et al (21) reported that the frequency of AECOPD in the past year was the best predictor of recurrence in patients with AECOPD (OR: 4.30, 95\% CI: $3.58,5.17, p<0.001)$. If a patient has suffered from AECOPD less than three times on average during one year, then mortality will increase and the health status will decrease after every acute exacerbation (22). Therefore, the frequency of acute exacerbations is an important prediction factor for short- and long-term prognosis. Garcia-Aymerich et al (23) found that severe AECOPD at any stage was an important factor that increases short- and long-term mortality. Our findings support this.

There were some limitations to this study and analysis. Because the sample was small, the results could be subject to bias. More intensive research is still required to explore gender differences in the prognosis of patients hospitalized with AECOPD.

\section{ACKNOWLEDGEMENTS}

We would like to thank the many families, physicians and technicians who have participated in this study, as without them, this work would not have been possible.

\section{REFERENCES}

1. Cydulka RK, Rowe BH, Clark S, Emerman CL, Rimm AR, Camargo CA Jr. Gender differences in emergency department patients with chronic obstructive pulmonary disease exacerbation. Acad Emerg Med 2005; 12: 1173-9.

2. Celli B, Vestbo J, Jenkins CR, Jones PW, Ferguson GT, Calverley PM et al. Sex differences in mortality and clinical expressions of patients with chronic obstructive pulmonary disease: the TORCH experience. Am J Respir Crit Care Med 2011; 183: 317-22. doi: 10.1164/rccm. 201004-0665OC. Epub 2010 Sep 2.

3. van Haren-Willems J, Heijdra Y. Increasing evidence for gender differences in chronic obstructive pulmonary disease. Womens Health (Lond Engl) 2010; 6: 595-600. doi: 10.2217/whe.10.37.

4. Tashkin D, Celli B, Kesten S, Lystig T, Decramer M. Effect of tiotropium in men and women with COPD: results of the 4-year UPLIFT trial. Respir Med 2010; 104: 1495-1504. doi: 10.1016/ j.rmed.2010.03.033. Epub 2010 Apr 24.

5. Executive Committee, Global Initiative for Chronic Obstructive Lung Disease (GOLD). Global strategy for the diagnosis, management, and prevention of chronic obstructive pulmonary disease. 2011 [updated 2013]. Available from: http://www.goldcopd.org/uploads/users/files/ GOLD_Report_2013_Feb20.pdf

6. Respiratory Branch of Chinese Medical Association. The guidelines of diagnosis and treatment for chronic obstructive pulmonary disease (revised 2007). Chin J Tuber Respir Dis 2007; 30: 8-17.

7. Watson L, Vestbo J, Postma DS, Decramer M, Rennard S, Kiri VA et al. Gender differences in the management and experience of chronic obstructive pulmonary disease. Respir Med 2004; 98: 1207-13.

8. De Torres JP, Casanova C, Hernández C, Abreu J, Aguirre-Jaime A, Celli BR. Gender and COPD in patients attending a pulmonary clinic. Chest 2005; 128: 2012-6.

9. Lopez Varela MV, Montes de Oca M, Halbert RJ, Muiño A, PerezPadilla R, Tálamo C et al. Gender related difference in COPD in five Latin American cities: the PLATINO study. Eur Respir J 2010; 36: 1034-41.

10. Carrasco-Garrido P, de Miguel-Díez J, Rejas-Gutierrez J, MartínCenteno A, Gobartt-Vázquez E, Hernandez-Barrera V et al. Characteristics of chronic obstructive pulmonary disease in Spain from a gender perspective. BMC Pulm Med 2009; 9: 2. doi: 10.1186/14712466-9-2.

11. Song DM, Qiao R, Huang S, Chen JF. Clinical characteristics of elderly women with coronary atherosclerotic heart disease. Anhui Medical 2009; 30: 521-3.

12. Liu SH, Zou H, Guo WY. The effect of hormone and its proportion in postmenopausal females who suffer from coronary heart disease. Clin Med China 2001; 17: 204-5.

13. Gu SY, Li QY, Wan HY. Research progress of women with chronic obstructive pulmonary disease. Int J Respiration 2009; 29: 150-3.

14. Yao WZ, Sun DJ, eds. The hot issues of chronic obstructive pulmonary disease. Beijing: People's Health Publishing House; 2009: 101-11.

15. Han MK, Agusti A, Calverley PM, Celli BR, Criner G, Curtis JL et al. Chronic obstructive pulmonary disease phenotypes: the future of COPD. Am J Respir Crit Care Med 2010; 182: 598-604.

16. Cooper CB, Waterhouse J, Howard P. Twelve year clinical study of patients with hypoxic cor pulmonale given long term domiciliary oxygen therapy. Thorax 1987; 42: 105-110.

17. Machado MC, Krishnan JA, Buist SA, Bilderback AL, Fazolo GP, Santarosa MG et al. Sex differences in survival of oxygen dependent patients with chronic obstructive pulmonary disease. Am J Respir Crit Care Med 2006; 174: 524-9. 
18. Voelkel NF, Tuder R. COPD: exacerbation. Chest 2000; 117 (Suppl 2): S376-9.

19. Wilkinson TM, Patel IS, Wilks M, Donaldson GC, Wedzicha JA. Airway bacterial load and FEVl decline in patients with chronic obstructive pulmonary disease. Am J Respir Crit Care Med 2003; 167: 1090-5.

20. Arnedillo Muñoz A. Impact of exacerbations and admissions in chronic obstructive pulmonary disease. Arch Bronconeumol 2010; 46 (Suppl 8): $8-14$.
21. Hurst JR, Vestbo J, Anzueto A, Locantore N, Müllerova H, Tal-Singer $\mathrm{R}$ et al. Susceptibility to exacerbation in chronic obstructive pulmonary disease. N Engl J Med 2010; 363: 1128-38.

22. Li JS, Wang MH, Yu XQ. The index of evaluating the condition and therapeutic effect of chronic obstructive pulmonary disease. Chin J Gerontol 2010; 30: 118-20

23. Garcia-Aymerich J, Serra Pons I, Mannino DM, Maas AK, Miller DP, Davis KJ. Lung function impairment, COPD hospitalisations and subsequent mortality. Thorax 2011; 66: 585-90.

Submitted 05 Sep 2013

Accepted 20 Jan 2014

Published 19 Mar 2014

Online: http://myspot.mona.uwi.edu/wimjopen/article/49

(C) Yu et al 2014.

This is an open access article made freely available under Creative Commons Attribution 4.0 International (CC BY 4.0). Users are free to share, copy and adapt this work as long as the copyright holder (author) is appropriately and correctly credited. See http://creativecommons.org/ licences/by/4.0/deed.en_us for more information. 